\title{
RESEARCHERS AS MEDIATORS BETWEEN POLICYMAKERS AND PRACTITIONERS - DO THEY HAVE THE NECESSARY SKILLS?
}

\author{
Adriana Zaiț $^{1}$
}

\begin{abstract}
Scientific research is nowadays a larger endeavor than ever, and researchers more than ever overwhelmed by questions of purpose, trust and future prospects, seen as either saviors and providers of solutions, or cash generating machines through altered and irreproducible results. Research is conducted in various social structures contexts, which shape everything from the questions asked within a society to the way responses given by researchers are used by policymakers and companies. It is no surprise, in these conditions, that they are often in the middle between policymakers as providers of regulations and funding, and practitioners as providers of markets for the products and ideas obtained through scientific research. Skills required for such a mediation process, for the complex array of informative interactions among various groups of stakeholders and interests are huge, way beyond technical knowledge and abilities in their field of specialization. But are they prepared for this role, as long as educating researchers doesn't necessarily go farther than providing them the methodological background for doing research? Scientific rigor and managerial relevance, communication and education have very different facets for policymakers and for practitioners, and researchers often lack the skills for this ambiguous game of instrumental, conceptual and strategic knowledge development and utilization. The aim of the present study is to analyze the skills inventory necessary for the modern researcher, as perceived by junior researchers, and the way ICTs, eDemocracy and civic participation could help shaping the researcher as mediator between politicians and practitioners. Literature review, indepth interviews with junior researchers and content analysis are used from a methodological point of view.
\end{abstract}

\section{Introduction - context and objectives}

Societies all over the world are more and more confronted with the rapid evolution of various positive advancements and also intricate crises (financial, economic, social, moral, political, health, education, democracy etc.) Various stakeholders are looking for or expecting solutions. Governments and research institutions are among those struggling for finding and applying solutions, and a large civic participation provides the healthy environment for these endeavors. The role of researchers becomes significant in ensuring a long-term success, including for the modern forms of e-Societies - e-Democracy and e-Governance. From all stakeholder categories (i.e. citizens, service users, businesses, public administrators, government agencies, not for profit entities, politicians, educators), researchers are the most complex one, with multiple facets and multiple roles: they are specialists in their fields, citizens and constituents of the public opinion, members of funding agencies and administrative entities, sources of information and educators,

${ }^{1}$ University “Alexandru Ioan Cuza” Iaşî, Romania 
influencers and beneficiary of research results, at the same time. But are they prepared to perform all these roles, do they have the necessary abilities for being such a complex actor and interface, at the same time? This is the main question of the present study, an exploratory one, meant to clarify the mediating position of researchers in the present, post-modern society. The main objectives are to synthesize the roles and skills for modern researchers, according to the literature, and identify the perceptions of researchers toward their mission in the present society.

\section{Skills for research and a search for new skills - a literature review}

A thorough literature review was performed, at the intersection of three fields - research (theoretical and applied, academic and business research, researchers skills and abilities, research results' use and dissemination etc.), public policies and strategies (policymakers, politicians, governments, decisions etc.) and e-governance (social media role, e-democracy, e-government stakeholders etc.). This documentary study allowed us to obtain a detailed view of researchers roles and correspondent skills, as emphasized in previous studies.

There are very few comparative analyses of the roles and perspectives of various categories of stakeholders, as previous studies discovered, as well (Yildiz, 2007; Rowley, 2011), and almost none considering researchers as a separate important stakeholder category. Yildiz considers that a better explanation of stakeholders' participation requires an enhanced understanding of the e-government process, which has a definitional vagueness at this time, so more research should be done in the field. Rowley's study is the only one found in which the typology of e-government stakeholders roles includes researchers and evaluators as a separate category (12 categories are identified people as service users, people as citizens, businesses, small-to-medium sized enterprises, public administrators, other government agencies, non-profit organizations, politicians, e-government project managers, design and IT developers, suppliers and partners, researchers and evaluators). Only two other studies mention research institutions (Heeks, 2003) and researchers (Millard, 2008) among various interest groups and roles. Overlaps and conflicts may also be present when talking about researchers' roles and interests, with several distinct value dimensions - technical (own specialty), financial, social, political, personal (identity and career). The societal values, as a whole, have changed in time, from liberal ones during the $18^{\text {th }}$ century, through democratic values $\left(19^{\text {th }}\right)$ and social values $\left(20^{\text {th }}\right)$, to empowerment values in 21th century (Millard, 2010), and researchers values and roles changed or should change accordingly; researchers cannot limit anymore to their technical-innovative, specialized and somehow isolated role of discoverers, they need to be active participants to the civic life of their communities.

One important barrier for researchers' increased participation and mediating role relates to the different professional cultures of various stakeholders categories (Ginsburg \& Gorostiaga, 2001; Anderson, Herriot \& Hodgkinson, 2011; Hanover Research, 2014; Rex, 2015). If we are looking just at researchers and economic environment representatives we can see that the first category highly values scientific rigor, while the second category places a great weight on practical relevance; irrelevant theory and invalid practice could lead to inefficient fragmentation of efforts and a lack of sense in research. As Anderson, Herriot \& Hodgkinson (2011) found, a 2 x 2 model of research or science exists, in terms of high and low levels of relevance and rigor, in which we can talk about four major types of science - pedantic (high rigor, low relevance), pragmatic (high rigor, high relevance), popularist (low rigor, high relevance) and puerile (low rigor, low relevance). Academic researchers tend to be pedantic, organizational clients and companies tend to be popularist, and from their contradictory struggle science is rather loosing, becoming puerile. In order to move to the pragmatic level, researchers should engage more in civic and especially 
political activities, in order to equilibrate expectations and influences of various stakeholders and to find a common language, rigorously correct, yet easy to understand by non-specialists in the field. The measures of success for researchers' outputs need to move from selfish ones, in which the researcher is the main beneficiary (publications, evaluation indexes, promotion etc.), to serviceoriented ones, in which the accent is on others - economic, social, cultural etc. - benefits (Kern, 2011).

In order for such a change to take place, researchers' "normal", usual skills, related to methodological rigor, specialized knowledge in the field, analytic accuracy, scientific enthusiasm, resilience etc. are not enough. Political skill, defined as an ability to effectively understand others at work and use knowledge to influence others to act in ways that enhance one's personal and/or organizational objectives (Ferris et al, 2005; Ferris et all, 2007; Treadway et al, 2010; Blickle et al, 2011; Grieve \& Mahar, 2013), becomes a "must have". This complex political skill has cognitive, affective and behavioral manifestations, influencing both directly and indirectly the outcomes of research, as it was long time ago hypothesized (Pfeffer 1981, Mintzberg 1983), and as recent studies have shown (Treadway et al, 2010; Braddy \& Campbell, 2014; Langer \& Stewart, 2016; Wise, 2016).

Academic research is crucial for the process of informing government policy (Rex, 2015), and researchers should take up more advisory roles, engage as much as possible with policy makers. Rex metaphorically speaks about researchers as providers of "a ladder out of the ivory tower". If they want to make a difference, researchers need to learn political skills, the art of drawing the correct lines between allowed, banned and controlled approaches, so that they could enable societies to develop (Alexander, 2016). The basic political skills would allow researchers to make their findings accessible to both politicians, who have the power as decision makers, and to the public, as final and real beneficiary. Impact becomes a driver (Smith, 2012), as scientists might have the freedom to decide what research to support, from a scientific point of view, but the research councils, often with political involvement, are those that sets strategic goals in order to contribute to economic growth and social development.

As Wise (2016) noticed, skills are at the heart of productivity and growth, at both personal, collective and social level, but they are also regionally sensitive, suggesting that some sort of skills ecosystems are needed in order to obtain the best impact - and political skills are definitely regionally defined and culturally affected and should be considered in such an ecosystem. They are strongly related to a larger category of skills, labeled as social intelligence (Grieve \& Mahar, 2013), which includes social skills, social information processing, social awareness and also connects with emotional intelligence and empathy. Four distinct practices are usually associated with political skill as general ability to maximize and leverage relationships in order to achieve individual, team and organizational goals (Ferris et al, 2005; Braddy \& Campbel, 2014): social awareness or astuteness (as the ability to observe others and understand their behaviors and motives); interpersonal influence (as a person's ability to influence and engage others, in a compelling and charismatic style); networking (ability to build relationships across and outside the organization); sincerity (ability to be forth right, open, honest and genuine with other people). This is the type of skill one would also expect to find in the category of transversal and transferable skills (Bimrose et all, 2007), highly valued, on theory, yet les often really developed at academic level, unfortunately.

When they disseminate their research results, researchers usually target other researchers, publishers and financing bodies but, as Langer \& Stewart (2016) stated, "piles of evidence don't make any difference if they're not used to develop policy". This suggests that researchers should 
tailor and address their communication of research findings to policy makers, as well, especially considering various orientations and parties, because policymakers of different political colors can act as bridges between groups and departments, increasing the interdisciplinary and applied focus. This approach is not an easy one and it is not risk free, there is a long history of concern with the impact of research on policy (Ginsburg \& Gorostiaga, 2001). It is almost common practice that vital decisions in a country are often taken without sufficient information or sound knowledge, sometimes from ignorance, sometimes due to honest limits, and sometimes deliberately, for political reasons. Ginsburg and Gorostiaga (2001) speak about three large types or categories of knowledge utilization, two positive and one negative. The positive ones are instrumental and conceptual use, and the negative one is dangerously labeled strategic, although it is considered a knowledge misuse. In the instrumental approach knowledge from research is used directly in making specific decisions, in processes which are of knowledge driven type (basic or theoretical, fundamental research, followed by applied research, development and application in economy and society) or problem solving type (a policy problem is identified, research is performed and a solution is suggested). The conceptual type is more complex and diffuse, rather indirect, and consists of two sub-categories of knowledge use, interactive and enlightenment type. In the interactive approach research findings are used by policymakers together with their own political experience and along with opinions from various other economic and social actors, in a non-linear, complex process of decision. In the enlightenment type of approach, scientific concepts and research results are spread in the whole society, through some type of diffusion process, thus shaping the decision makers' general way of thinking and becoming relevant to policy; it is a sort of educational process taking place in society, but the mechanisms are neither unique, nor simple to explain. The third type of use of research knowledge, the negative one, has three sub-categories political, tactical and promotional. In the political type of use, research findings are considered and applied selectively, to support a previously adopted political decision - only results supporting a specific position are actually taken into consideration, contrary ones being ignored. In the tactical type, research is used to enhance the credibility of policymakers and actions or - quite often - lack of action. Research results are rather excuses or status building accessories among politicians. Finally, in the promotional type research serves to disseminate and promote the implementation of a specific policy to individuals and groups who were not involved in the decision-making process. These types of uses can take place continuously, all the time, but can also prevail in specific stages of the political process, as Klemperer, Theisens \& Kaiser (2001) suggest. In their view, not always supported by empirical facts, the conceptual enlightenment occurs more often in the design stage of policies, the strategic political one during the decision stage and the instrumental problem solving one during the implementation stage. Various supplementary problems arise, due to the different cultural backgrounds of researchers and policymakers, researchers being usually seen as more objective, in favor of factual knowledge and dispassionate, universal truth, while policymakers are usually perceived as subjective, partial, biased, incomplete, focusing on self-serving and politically compromised knowledge. However, solutions exist for the mediation of this complex process between researchers and policymakers, six approaches being suggested toward enhancing the connections and collaboration among theorists, researchers, practitioners and policymakers: translation, education, role expansion, decision oriented research, collaborative action research and collective research and praxis. For the first translation approach, researchers are mediators, labeled as research brokers or linkers, supposed to find a common language for all stakeholders. The education approach goes a bit further, for both researchers and policymakers, but it remains a question of superficial transformations, at the surface - focus on communication and negotiation, rather than common work. Role expansion suggests the involvement of every category in the activities of the others - practitioner research, policy assisting roles for researchers - it is the start of actually being in the other category's shoes. The last two forms, the most evolved ones, require 
more and more joint reflexion and action, co-learning and real collaboration for a common societal aim. No matter what the adopted solution is - simple translation or real collaborative work - the first step is to prepare researchers to the political skill type of abilities necessary to generate the positive change, otherwise the process cannot be initiated. But do we prepare researchers for such a job? The answer is rather no, at this moment - political skill doesn't appear in academic curricula or research institutions job descriptions, all over the world, and both academia and research entities are rather reluctant to engage in policymaking consulting or joint activities.

\section{Researchers as mediators - methodology and results}

In order to find out what researchers think about supplementary skills in the e-society, without any hint about the purpose of the study, not to influence their opinions in any way, we performed a loosely structured exploratory study. The exploratory study consisted of a semi-structured qualitative survey with 12 junior doctoral researchers. They all received 5 open questions, for which the answers were provided individually, in a written format; the whole process took one hour, every researcher taking as much time as needed in order to reflect and answer. The questions were: (1) What is the main role or mission of a researcher nowadays, in the present society? (2) Apart from the specific research skills, what other abilities would be useful for a researcher? (3) Who could and should use the research results, and how could this be done? (4) How do social media and eGovernance influence the position and mission of researchers? (5) Thinking of your overall research experience, please tell which is the most representative story/happening/memory you could share? We selected the first four questions in relation with the main issues identified in the literature review (researchers' roles in society, skills for researchers, use of research results, research and egovernance) and our main research question (do researchers have the skills required to accomplish their complex role in the e-society). The last question was a story telling type, designed for indirectly and most credibly obtaining information about the most important issues in the research activity of the interviewed researchers. Questions were addressed one by one, in a logical sequence, with time for answering in between, so that respondents would not be influenced by the final aim. The data collection method is a mixture of interviewing, qualitative survey and group interview, with certain advantages in terms of time and ease of collecting.

Answers were analyzed using an emergent coding content analysis procedure, with no preestablished categories, due to the exploratory intent of the research. Written texts were read three times - first time for getting a general idea or image, second time for identifying main categories (presence of specific issues of interest) and the third time in order to evaluate weight (most frequent issues for every researcher and for the whole group of 12) and affect (positive-negative, optimisticpessimistic). We will present the finding in the next paragraphs.

For the first question, concerning the perceived mission of the researchers, 6 answers were unidimensional - one single important mission, 5 bi-dimensional - two related missions and one tridimensional. As single important mission (present in all 12 answers) it was seen the contribution to the positive evolution of the society, with small variations (development of science for a better life, providing solutions for the society, bringing benefits to the society, finding relevant answers for the population, offering explanations for the changes in the modern society). A second mission (present in 5 answers) was related to finding causal explanations, influencing human behavior, becoming a binder between economic, academic and legal environment, bringing novelty or obtaining innovation (not necessarily connected to practical solutions to be applied in society). The third mission was related to the ability of making predictions, knowing what the future will bring. Although all missions are interconnected, the practical side of the research was emphasized - the 
positive development of society - but at a very general level, without specific issues being discussed.

For the second question the junior researchers provided a list of supplementary skills related to the "soft" abilities - communication (mentioned 5 times), perseverance (mentioned 3 times), passion (mentioned twice), attention to details (mentioned twice), courage, patience, confidence, openmindedness, flexibility, socialization, team working, human interaction, entrepreneurial spirit, empathy, time management, desire to learn, cultural sensitivity.

The third question - a double one - had precise answers only for the first part - who could/should use the research results. In terms of how, only three answers were given - when decisions are taken, when it's a need and through the creation of an appropriate framework - again, very vague, general answers. As for users, four categories of stakeholders were - mentioned: government and state institutions ( 9 answers), business environment and companies (6 answers), academic and research entities (5 answers), civic society (3 answers).

For the fourth question there were two aspects investigated - the presence of specific influences and the direction of those influences, positive or negative. Only three researchers gave negative interpretations for the social-media effects - too many information and too little time for analysis, lack of credibility, manipulations possible, and errors of interpretation. Two of them only gave negative effects, one talked about both positive and negative influences at the same time. As for the positive influences, they were mainly related to easy and rapid access to information, for both documenting and disseminating results (10 answers). One answer concerned the positive pressure of social media channels on entities which are supposed to use the research results (talking about social media as a new power in a state), one about the smaller distance between researchers and consumers of research results, talking about a researcher's stepping down from the pedestal, out of the usual "bubble", and one about the shorter time between discovery and application of research results, through convincing political decisional factors about the opportunity of research results implementation.

The story telling was least successful, due to the written form, most probably, but also to the limited experience of the junior researchers. Stories were very short, not elaborated. 3 of the researchers said only that they would talk about a specific issue (finding out others' opinions for their research, explaining an intended model of research and what is the position of the researcher), without providing the real story (they only said they would tell this story). The other stories shown the importance placed by researchers on the recognition of their efforts and results (the fact that they received appreciation from the coordinator, they succeeded to go to a conference or publish an article, they were able to find other people doing similar things and appreciating their work) or the difficulties encountered in their research endeavors (lack of data, lack of cooperation from the part of the investigated companies, fear that the results would not be those expected, desire to give up, fear that everything was already researched and said and nothing new could be discovered).

On total the researchers seem to be aware of the fact that they have a special role to play for the advancement of the society, but without offering precise details about this role. They did not emphasize other potential roles, either - users of research results, influencers or consultants, for example. They have a rather passive position as far as the use of the research findings is concerned - a perspective in which their research results should be used by state institutions, companies and the academic environment, mainly, without a particular initiative from their part. It looks like their mission is rather to do research, and then somebody else should actually use the results in order to 
produce the positive evolution in society. The social media is seen as very important, but again more as an information and communication channel. As for skills, most of the answers focused on general communication and other soft skills related to research - attention to details, courage, curiosity, openness, perseverance. There were no answers related to social astuteness, interpersonal influence, networking and sincerity, as potential dimensions of the political skill inventory. The story telling didn't bring anything new concerning situations in which the political skills would be needed, meaning that at an exploratory stage, with a totally open discussion, junior researchers don't seem to be aware of a need for political skill.

\section{Conclusions}

The specialized literature shyly writes about researchers as distinct and important stakeholders in the modern society or about their complex, multiple role. The impact of research on practice and policy is questioned and worrying, yet specific approaches and instruments for improving this impact are not developed. The way policymakers use research results is not always positive, and the professional culture differences between researchers and policymakers are large, recognized but still not treated. However, studies already draw attention on the potentially significantly positive consequences of the real collaborative approaches between researchers, practitioners and policymakers. Special political skills are needed for this collaborative process, and even if the subject is rather old, starting back in the 80's, it's only lately that investigators conceptually defined and conceived operational measures for the new type of abilities (2005, through the Ferris et all approach of defining and measuring the political skill construct).

An exploratory study on 12 junior academic researchers ( $\mathrm{PhD}$ level, from the field of economics and business administration, sub-fields accounting, computer science, economics, international relations, finance, management, marketing, statistics) has shown that researchers are aware of their special role in the advancement of the society and making life better, but without seeing the precise details of this role or how it could be performed. They did not emphasize other potential roles, as for example users of research results, influencers or consultants, roles suggested by Rowles (2011). They have a rather passive position toward the use of their research findings; their research results should be used by state institutions, companies and the academic environment, mainly, but apparently without any particular initiative from their part, they don't seem to acknowledge their contribution in initiating such a process. It looks like their mission is rather to just do research, and then somebody else should actually use the results in order to produce the positive evolution in society. The social media is seen as very important as an information and communication channel, and less for a real participation to the e-governance process. As for supplementary skills needed by researchers, most of the answers focused on general communication and other soft skills connected with research - attention to details, courage, curiosity, openness, perseverance. There were no answers related to social astuteness, interpersonal influence, networking and sincerity, as potential dimensions of the political skill inventory. The story telling didn't bring anything new concerning situations in which the political skills would be needed, meaning that at an exploratory stage, with a totally open discussion, junior researchers don't seem to be aware of a need for political skill.

Certain limits exist for the present study - the scarce literature in the field, the delicate subject of the relationship between research and policymaking, the small sample for the exploratory study. However the results are encouraging for future research, extended on senior researchers from research entities, having a permanent research job, and on policymakers, to catch the other side of the equation. The present results should serve as a reflective signal for the academic environment, 
concerning the need for developing political skills for future researchers, if we want research results to have a real, positive impact in society.

\section{References}

[1] AleXANDER, T. (2017), Practical Politics: Lessons in Power and Democracy, Trentham Books, Kindle Edition.

[2] ANDERSON, N., HERRIOT, P., HODGKINSON, G. P (2001), "The practitioner-researcher divide in Industrial, Work and Organizational (IWO) Psychology: where are we know and where do we go from here?", Journal of Occupational and Organizational Psychology, 74, pp.391-411.

[3] IMROSE, J., BARNES, S-A, BROWN, A., HASLUCK, C., BEHLE H. (2007), "Skills diagnostic and screaning tools: a literature review", Research Report $n .459$, Department for Work and Pensions, under licence from the Controller of Her Majesty's Stationery Office by Corporate Document Services, Leeds, St Clements House, 2-16 Colegate, Norwich NR3 1BQ.

[4] BLICKLE, G. et al (2011), "Fit of the political skill to the work context: a two study investigation", Applied Psychology: an International Review, pp.1-28.

[5] BRADDY, Ph., CAMPBELL, M. (2014), "Using Political Skill to Maximize and Leverage Work Relationships", White Paper, Center for Creative Leadership.

[6] CHAMORRO- PREMUZIC, T., ARTECHE, A., BREMNER, A.J., GREVEN C., FURNHAM, A. (2010), "Soft skills in higher education: importance and improvement ratings as a function of individual differences and academic performance", Educational Psychology, Vol. 30 , Iss. 2, p.221-241.

[7] COOLE, D. (2007), "Expansion and validation of the Political Skill Inventory (PSI ): An examination of the link between charisma, political skill, and performance", Graduate Theses and Dissertations, http://scholarcommons.usf.edu/etd/680.

[8] FERRIS, G. et al (2007), "Political skill in organizations", Journal of Management, 33(3), pp.290-320.

[9] FERRIS, G. et al. (2005), "Development and Validation of the Political Skill Inventory," Journal of Management, Vol. 31 No. 1, February 2005 126-152.

[10] GINSBURG, M., GOROSTIAGA, J. (2001), "Relationships between Theorists/Researchers and Policy Makers/Practitioners: Rethinkingthe Two- Cultures Thesis and the Possibility of Dialogue", Comparative Education Review, Vol. 45, No. 2, Special Issue on the RelationshipsBetween Theorists/Researchers and Policy Makers/Practioners (May 2001), pp. 173-196.

[11] GRIEVE, R., MAHAR, D. (2013), "Can social intelligence be measured? Psychometric properties of the Tromsø Social Intelligence Scale - English Version, The Irish Journal of Psychology, 34:1, 1-12, DOI: 10.1080/03033910.2012.737758. 
[12] Hanover Research (2014), "Buiding a culture of research: recommended practice", Academy Administration Practice report, p.1-33.

[13] HEEKS, R. (2003), "Most e-government-for-development projects fail; how can the risk be reduced?”, IDPM, http://idpm.man.ac.uk/publications/wp/igov/index.shtml.

[14] HODGKINSON, G. P., HEALEY, M. P. (2008), “Toward a (Pragmatic) Science of Strategic Intervention: Design Propositions for Scenario Planning+, Organization Studies, 29(03): 435457.

[15] KERN, S. (2011), "Analytic model for academic research productivity having factors, interactions and implications", Cancer biology \& therapy, 12, pp.949-956.

[16] KLEMPERER, A. M., THEISENS, H. C., KAISER, F. (2001), "Dancing in the dark: the relationship between policy research and policy making in Dutch Higher Education", Comparative Education Review, vol.45, iss.2, pp. 197-219.

[17] LANGER, R., STEWART, R. (2016), “The science of using rsearch: why it starts with the policymaker", The Conversation, http://theconversation.com/the-science-of-using-researchwhy-it-starts-with-the-policymaker-59265.

[18] MEDAGLIA, R., ZHENG, L. (2017), "Mapping government social media research and moving it forward: A framework and a research agenda", Government Information Quarterly 34, 496-510.

[19] MiLLARD, J. (2010), "Government 1.5 - is the bottle half full or half empty?", European Journal of ePractice, nr.9, www.epracticejournal.eu .

[20] MILLARD, J. (2008), "EGovernment measurement for policy makers", European Journal of ePractice, nr.4, www.epracticejournal.eu.

[21] MINTZBERG, H. (1983), Power in and around organizations, Englewood Cliffs, NJ: Prentice- Hall.

[22] NYGAARD, L. P. (2017), "Publishing and perishing: an academic literacies framework for investigating research productivity", Studies in Higher Education, 42:3, 519-532, DOI:10.1080/03075079.2015.1058351.

[23] PANDA, A., GUPTA R. (2014), "Making academic research more relevant: a few suggestions", IIMB Management Review 26, 156-169.

[24] PFEFFER, J. (1981), Power in organizations, Boston: Pitman.

[25] REX, H. (2015), "How does academic research contribute to the work of government? Networks of evidence and expertise for public policy", http://www.csap. cam. ac.uk/news/article-how-does-academic-research-contribute-work-governm/.

[26] ROWLEY, J. (2011), "e-Government stakeholders-Who are they and what do they want?", International Journal of Information Management 31 (2011) 53-62. 
[27] SMITH, A. (2012), "Making an impact: when science and politics collide", The Guardian, https://www.theguardian.com/science/2012/jun/01/making-impact-scientists.

[28] TREADWAY, D. C., BRELAND, J.W., WILliAMS, L.M., CHO, J., YANG, J., FERRIS, G.R. (2011), "Social Influence And Interpersonal Power In Organizations: Roles Of Performance And Political Skill In Two Studies, Political Skill, Performance, And Power, p.1-48.

[29] WISE, G. (2016), "Deceloping productive places: the role of universities in skills ecosystems", University Alliance Regional Leadership series, pp.1-28.

[30]. YILDIZ, M. (2007), "E-government research: reviewing the literature, limitations and ways forward", Government Information Quarterly 24 (2007) 646-665. 